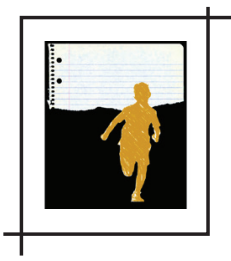

\title{
$O$ DIREITO ÀS CULTURAS DA INFÂNCIA: INDICADORES NO CURRÍCULO MUNICIPAL DE SÃO CAETANO DO SUL
}

\author{
Milene Valentir Ugliara* \\ Patrícia David** \\ Raquel Romano Correa*** \\ Sérgio Oliveira dos Santos****
}

Resumo: Este ensaio tem como propósito observar e analisar indicadores no documento do Currículo Municipal de São Caetano do Sul que tratam direta ou indiretamente do direito às culturas da infância. Metodologicamente se elaborou um quadro referência com alguns elementos estruturantes das culturas da infância para relacioná-lo com três partes do currículo: os princípios norteadores, a educação infantil e o ensino fundamental l. Observou-se que o curriculo em análise apontou diversos indicadores em favor do direito às culturas da infância, de forma mais presente no texto da educação infantil e mais indireta nos textos do fundamental I, por ocupar-se em maior grau dos componentes curriculares.

Palavras-chave: Culturas da infância. Criança. Educação infantil. Ensino fundamental. Currículo.

\section{INTRODUÇÃO}

Este ensaio pretende trazer ao debate público os principais indicadores que problematizem, observem e contemplem, em primazia, o direito às culturas da infância no Currículo Municipal de São Caetano do Sul (SECRETARIA MUNICIPAL DE EDUCAÇÃO DE SÃO CAETANO DO SUL, 2020).

\footnotetext{
* Mestre em Arte Educação pelo Instituto de Artes da Unesp. Graduação em Educação Artística com habilitação em Artes Cênicas e Visuais pelo Instituto de Artes da Unesp. Graduada em Filosofia pela Universidade São Judas Tadeu. E-mail: milenevalentir@ scseduca.com.br

** Mestre em Distúrbios do Desenvolvimento. Graduação em Educação Física pela UniABC. Atua com processo de inclusão educacional de estudantes com deficiência no ensino público.E-mail: patriciadavid@scseduca.com.br

*** Mestre em Educação pela Umesp. Lato Sensu em Psicopedagogia pela UniABC e Supervisão Escolar pela FIJ-RJ. Graduação em Pedagogia pela UniABC. E-mail: raquelcorrea@scseduca.com.br

*** Mestre e Doutor em Educação pela Umesp. Professor na PMSCS.E-mail:sergiosantos@scseduca.com.br
} 
0 fenômeno abordado, portanto, será a observância textual, preponderantemente conceitual, que revela e declara os princípios que regem os direitos e as garantias da infância.

Metodologicamente, como eixo para as observações e análises, tomaremos como referência alguns elementos estruturantes que marcam as culturas da infância. A partir daí, passaremos a observar três dimensões do Currículo Municipal: 1. o texto introdutório e seus princípios; 2. o documento referencial da educação infantil; 3. os textos introdutórios dos componentes curriculares do ensino fundamental I.

\section{ELEMENTOS ESTRUTURANTES DAS CULTURAS DA INFÂNCIA}

Quando as crianças adentram o universo cultural, por meio do seu nascimento biológico, inserem-se em meios culturais já desenvolvidos de acordo com sua condição social, seu local de nascimento e as características familiares de que fazem parte. Esse contato biológico com o mundo social já coloca as crianças em um universo de regras e limitações que são definidas aquém das suas necessidades, pois mobilizam o fazer, as necessidades e o tempo dos adultos. Em contrapartida, as crianças, por serem dotadas das características que permeiam a faixa etária que constitui principalmente a primeira infância, já nos mostram que há peculiaridades nas suas relações com o mundo que as cerca.

Nessa linha de compreensão e relação das crianças com o mundo, é preciso considerar que elas se relacionam diretamente com as diferentes culturas produzidas pelo mundo adulto, mas nessa relação são capazes de construir algo que Ihes é significativo e particular, ou seja, um mundo próprio a partir das suas construções simbólicas.

Essa relação fica evidenciada quando observamos as crianças e identificamos um universo à parte, de múltiplas dimensões de acesso, entendimento, relações, expressões e criações que constroem e compõem as culturas da infância. Mas é possivel mapear os elementos essenciais que configuram tais culturas da infância?

Propomos essa configuração no Quadro 1, no qual apresentamos alguns elementos estruturantes ou essenciais que traduzem o modo de ser próprio dessa fase da vida denominada infância, o que, para efeito metodológico deste ensaio, será tomado como um referencial de observação do texto curricular. 
Quadro 1 Alguns elementos estruturantes das culturas da infância'

\begin{tabular}{c}
\hline ELEMENTOS ESTRUTURANTES/ESSENCIAIS - MODOS DE SER DA INFÂNCIA \\
\hline Leitura de mundos/interpretação por múltiplas linguagens. \\
Acionamento das dimensões sensiveis da corporeidade. \\
\hline Experimentações e explorações em realidades objetivas, subjetivas e intersubjetivas; \\
transfiguração de realidades. \\
\hline Diálogos da corporeidade com a pluralidade dos saberes culturais vividos em \\
temporalidade (reiteração) e espaços (territórios) próprios. \\
\hline Acionamento dos âmbitos da imaginação (mundo onírico) e da criatividade, próprios do \\
ato de brincar e jogar; diálogos entre o real e o imaginário. \\
Estabelecimento de enlaces, vínculos, relações e afetos.
\end{tabular}

Fonte: Elaborado pelos autores.

Vejamos a seguir o nosso primeiro objeto de análise: os princípios norteadores do currículo.

\title{
PRINCÍPIOS NORTEADORES DO CURRÍCULO MUNICIPAL DE SÃO CAETANO DO SUL
}

Atendendo a um pressuposto legal, o currículo do município de São Caetano do Sul (SECRETARIA MUNICIPAL DE EDUCAÇÃO DE SÃO CAETANO DO SUL, 2020, p. 17):

\begin{abstract}
[...] nutre-se na Constituição Federal (BRASIL, 1988), que afirma a educação como um direito subjetivo reservado a todos os bebês, crianças, adolescentes e jovens. Desse modo, o município de São Caetano do Sul reitera seu pacto expressamente assumido, salvaguardando o direito constitucional à educação, por meio da oferta de uma Educação Integral de qualidade, a fim de garantir o acesso e a permanência equânime na escola, a todos os sujeitos entre 4 e 17 anos, além dos que não puderam frequentá-la na idade exigida pela lei (BRASIL, LDB, 1996).
\end{abstract}

Uma educação de qualidade deve considerar a infância um universo cultural, em que as experiências cotidianas constroem o conhecimento coletivo. Não há como apostar em uma educação que caminhe com seus bebês e crianças para uma leitura de mundo (explorando

\footnotetext{
1 - Para a elaboração desse quadro referencial, adotamos o estudo de Josgrilberg (2017) sobre fenomenologia das idades da vida, com destaque para a fase puer. Trata-se, portanto, de um referencial fenomenológico-hermenêutico e antropológico, cujas delimitações intencionam traduzir os fenômenos e âmbitos próprios do modo de ser da infância em suas intersecções e diálogos com o mundo da cultura em seus respectivos tempos e territórios.
} 
as múltiplas linguagens e considerando o ato de brincar, como aponta o Quadro 1) se as experiências educativas não estiverem relacionadas a uma compreensão de educação que possibilite a concretude de tais propósitos.

Observamos que o currículo adota o compromisso com os Objetivos de Desenvolvimento Sustentável (ODS) sugeridos pela Organização das Nações Unidas - ONU (Agenda 2030 http://www.agenda2030.com.br/ ) especialmente no objetivo 4: "Assegurar a educação inclusiva e equitativa e de qualidade, e promover oportunidades de aprendizagem ao longo da vida para todos".

0 documento explicitou a importância de se considerar a diversidade do bebê e da criança em todas as suas dimensões. Observou-se que o currículo, como meio para viabilizar a diversidade e seus elementos subjacentes anteriormente descritos, aponta o conceito de território, um importante elemento para contemplar as culturas da infância.

0 território, na perspectiva da Educação Integral, não é só o espaço físico, no qual está inserida a comunidade e a escola, mas é, sobretudo, o "[...] chão mais a identidade". 0 sentimento de pertencer a um grupo, a um lugar; "[...] é o sentimento de pertencer àquilo que nos pertence" (SANTOS, 1999, p. 07). Todos os espaços (escolares e não escolares) passam a ter um potencial educativo, quando integrados de forma planejada e articulada (SECRETARIA MUNICIPAL DE EDUCAÇÃO DE SÃO CAETANO DO SUL, 2020, p. 20).

Também consta no documento de referência uma intenção em ofertar um projeto educativo em que os bebês e as crianças são vistos como sujeitos da construção dos seus saberes. Assim, potencializar uma educação que considere as relações de gênero, as relações étnico-raciais e com vistas para a educação especial (na perspectiva da educação inclusiva) também assume espaço.

A seguir, serão apontados os três princípios que o currículo defende como estruturantes, e trabalhar-se-á com a seguinte pergunta:

- Como a adoção desses princípios pode contribuir para a reverberação das essências das culturas da infância?

\section{0 princípio da equidade}

O conceito de equidade sugerido no currículo pressupõe reconhecer as diferentes condições de cada um e a necessidade de fomentar ações singulares, ou seja, ofertar múltiplos e distintos meios para assegurar equidade e promover aquilo a que os cidadãos têm direito: igualdade de oportunidades. Assim, reconhecer a necessidade de todos e todas e de cada um é ofertar aos bebês e às crianças uma convivência respeitosa com seus pares e no percurso 
dessa aprendizagem. Quando falamos das culturas da infância, não consideramos resultados, mas sim processos, respeitando o bebê e a criança na sua interação com o meio, desde que este ofereça oportunidades baseadas nesse princípio.

\section{0 princípio da educação integral}

Na perspectiva da valorização da cultura da infância, uma educação equitativa e integral pressupõe considerar os saberes dos bebês e das crianças advindos de suas realidades e experiências familiares e culturais, valorizando as diferentes linguagens; portanto, a diversidade do sujeito e do contexto. Priorizar o lúdico, as interações, o uso da imaginação e a leitura de mundo.

\section{0 conceito de inclusão}

A inclusão diz a respeito de todos e todas, sobre o respeito às suas diferenças. A proposta de uma educação inclusiva como apresentada no currículo considera todos, bebês e crianças, valorizando as diferenças e o atendimento à pluralidade e à diversidade cultural, resgatando e respeitando as várias manifestações de cada comunidade. Respeitar, valorizar e acolher a diversidade como um valor reconhece a diferença no modo de ser e, portanto, de fazer, de aprender e de intervir, trazendo a importância de se considerarem os tempos e espaços de aprendizagem como essenciais no cotidiano escolar.

Observamos que os princípios apontados no currículo possuem relevância conceitual que potencializa os elementos estruturantes das culturas da infância. A seguir, vamos analisar mais profundamente quando o currículo orienta a educação infantil.

\section{CULTURAS DA INFÂNCIA NA EDUCAÇÃO INFANTIL}

o Currículo Municipal tende a considerar as crianças como promotoras de uma cultura própria. Para isso, o currículo aponta marcos legais referenciando-se também por autores exponenciais na área. Propõe-se a entender e delimitar a criança e as necessidades da infância por meio de uma base conceitual (SECRETARIA MUNICIPAL DE EDUCAÇÃO DE SÃO CAETANO DO SUL, 2020, p. 85), de modo a considerar a infância e seus elementos, afastando-se de uma visão escolarizada.

Nessa base conceitual, a criança é entendida como um ser biológico que apresenta uma condição de maturação para avançar em seu desenvolvimento, um ser social que depende de uma interação com o outro para mediar o seu avanço no desafio daquilo que ainda não é competente para realizar com autonomia, que cria símbolos no ajuste à sua relação com o 
mundo, um ser emocional e corpóreo, em que a emoção e a razão caminham lado a lado em seu desenvolvimento, e em que a afetividade é condição para suas relações. Assim, o modo como o currículo entende a infância traz os elementos essenciais das culturas da infância presentes no Quadro 1.

Ainda na linha de construção de uma base conceitual, o currículo defende aprendizagem ativa, ou seja, faz-se necessário que esse sujeito esteja em ação para construir seus símbolos e conceitos sobre o mundo e criar suas próprias narrativas a partir das suas experiências, de acordo com seus diferentes níveis de interpretação da realidade, por meio das múltiplas linguagens.

Fechando essa linha de construção de uma fundamentação teórica que dá vista a essa criança, sujeito da sua infância, o currículo entende que as crianças constroem a sua própria inteligência, e os adultos devem fornecer-lhes as atividades e o contexto e, acima de tudo, devem ser capazes de estabelecer uma escuta sensivel.

Dessa forma, uma parte dos elementos que permeiam as culturas infantis é afirmada no documento por meio de sua fundamentação teórica sobre o desenvolvimento e a aprendizagem na infância. 0 documento curricular se compromete com essa premissa quando revela que,

[...] para atingir tal objetivo, o trabalho com a criança, na Educação Infantil, acontece por meio do lúdico, das explorações, do incentivo à imaginação e da criação, garantindo confiança, respeito e interação entre seus pares. Sendo assim, a educação é menos massificada e mais personalizada, respeitando o ritmo de cada criança (SECRETARIA MUNICIPAL DE EDUCAÇÃO DE SÃO CAETANO DO SUL, 2020, p. 86).

0 intuito do documento curricular é evidenciar o ser criança na sua naturalidade de ser, viver, conviver, conhecer e aprender.

Outro ponto presente no documento é que o próprio espaço e os ambientes organizados (SECRETARIA MUNICIPAL DE EDUCAÇÃO DE SÃO CAETANO DO SUL, 2020, p. 122) atuem de modo acolhedor e educador, perfazendo uma escola integradora que garante as inter-relações.

Com base nessas afirmações, o currículo da educação infantil reserva em um anexo as premissas sobre quanto esses espaços, os ambientes planejados, os materiais que são oferecidos às crianças e o que precisa se incorporar às paredes da escola são fundamentais para construir uma educação que assegure os valores da infância, assegure os direitos das crianças e construa o encanto necessário às bases de uma educação valorosa. "Um olhar sensível" (SECRETARIA MUNICIPAL DE EDUCAÇÃO DE SÃO CAETANO DO SUL, 2020, p. 231) é o nome dado a esse anexo, mas é também a proposição de uma forma de ser e estar do adulto na educação da infância. 
0 olhar sensivel do adulto se vincula aos elementos presentes nas culturas infantis e precisa construir contextos de aprendizagens que envolvam as crianças a partir do desejo de descobrir, de espaço para experienciar e de tempo para explorar.

Nessa perspectiva, é imprescindivel que a frase seguinte, extraída do documento, ganhe força e concretude no entendimento e nas ações docentes:

Na escola da primeira infância, entende-se a importância do olhar e do atendimento às necessidades dos pequenos, o respeito às diferentes linguagens e expressividade, além da organização de espaços e ambientes saudáveis e acolhedores, que estimulam as investigações, as interações, as descobertas e as aprendizagens, considerando a criança na sua individualidade e integralidade (SECRETARIA MUNICIPAL DE EDUCAÇÃO DE SÃO CAETANO DO SUL, 2020, p. 87).

Nessa relação do papel do adulto e da criança no processo educacional, o tempo se apresenta com outro valor. 0 documento faz essa relação do tempo da criança sobre uma necessidade preponderante à educação da infância e à garantia do respeito às suas culturas.

\footnotetext{
A sensibilidade do adulto ao lidar com os tempos das crianças - que têm ritmos, necessidades e desejos próprios de cada faixa etária e de suas individualidades - deve sempre permitir que elas descubram detalhes, relações, amizades, características e potencialidades durante suas ações cotidianas, para que continuamente desenvolvam uma autonomia que alimente a sua curiosidade natural (SECRETARIA MUNICIPAL DE EDUCAÇÃO DE SÃO CAETANO DO SUL, 2020, p. 92).
}

Observou-se no currículo que há uma preocupação em considerar os tempos próprios das culturas da infância em detrimento dos tempos da rotina gerida pelos adultos (SECRETARIA MUNICIPAL DE EDUCAÇÃO DE SÃO CAETANO DO SUL, 2020, p. 90-91).

0 documento curricular de São Caetano do Sul utiliza os campos de experiência (SECRETARIA MUNICIPAL DE EDUCAÇÃO DE SÃO CAETANO DO SUL, 2020, p. 108) como organizadores curriculares e se apoia nas divisões em faixas etárias que separam as crianças em bebês, crianças bem pequenas e crianças pequenas. No que concerne a cada campo de experiência, evidenciam-se os direitos de aprendizagem que são garantidos às crianças, as experiências de aprendizagem que beneficiam o desenvolvimento dos pequenos, as ações que são esperadas dos adultos para que a intenção se configure no cotidiano e, por fim, as considerações que dão significado a alguns dos pontos mencionados (SECRETARIA MUNICIPAL DE EDUCAÇÃO DE SÃO CAETANO DO SUL, 2020, p. 150), com o objetivo de fortalecer as fundamentações da educação que se almeja a partir do documento curricular. Como consequência dessas ações, pretende-se evidenciar o modo e as particularidades da cultura infantil. 
Nesse contexto, o currículo afirma que as crianças são sujeitos competentes e de direitos, que explicitam as regras da própria infância e que constroem seus próprios caminhos de desenvolvimento e aprendizagem por meio de suas experiências, mediados por adultos respeitosos pela sua potencialidade diante do cotidiano vivenciado.

Entender que a experiência possibilita que a criança se relacione com o meio a partir das suas inúmeras dimensões agrega valor e respeito a um tipo de construção cultural que assegura as características da infância e a coloca em toda a sua corporeidade no meio da instituição educacional, como revelam as intencionalidades didáticas do currículo:

É a experiência que mobiliza o sujeito e faz com que ele produza sentidos que podem ser acessados nas suas vivências em outras situações semelhantes, estabelecendo relações com o ambiente, com os objetos de estudo, com seus pares, com os adultos e consigo. A partir da experiência é possivel constituir um aprendizado em constante movimento, o que revela e influencia na dinâmica da nossa sociedade (SECRETARIA MUNICIPAL DE EDUCAÇÃO DE SÃO CAETANO DO SUL, 2020, p. 103).

Outro ponto que é fundamental à garantia das culturas infantis e que permeia a relação da criança com o mundo é o brincar. Observa-se que no curriculo o brincar não se resume a uma atividade que, em sua maioria, as crianças realizam apoiadas ou não em brinquedos e materiais similares, mas que precisa ser entendido como a linguagem que a criança utiliza para acessar o mundo à sua volta, refletir sobre ele e se propor a participar da vida na sociedade a que pertence.

0 brincar está presente no documento curricular como uma diretriz de todos os pressupostos de trabalho relacionados diretamente às crianças:

Sabe-se que o brincar é a atividade principal da criança. Por meio da brincadeira a criança faz escolhas, toma decisões, manifesta seus sentimentos e valores, interage, exercita o autocontrole e autoconhecimento, soluciona problemas, ressignifica o real, se constitui como indivíduo e sujeito social. A brincadeira é linguagem, as crianças "falam" por meio dela. Nessa perspectiva, a escola deve ser espaço de expressão plena e de interação. Brincar supõe um contexto social e cultural [...] (SECRETARIA MUNICIPAL DE EDUCAÇÃO DE SÃO CAETANO DO SUL, 2020, p. 100).

A valorização do brincar e das interações é o caminho mais eficaz para garantir os direitos da infância como um período rico de vivência e desenvolvimento do sujeito. Com essa premissa, o documento assegura que "a Educação Infantil, por meio do brincar, torna-se um rico espaço para que a criança desenvolva competências sociais fundamentais para a sua vida" (SECRETARIA MUNICIPAL DE EDUCAÇÃO DE SÃO CAETANO DO SUL, 2020, p. 101). 
Em meio às intencionalidades e aos princípios presentes no Currículo Municipal da cidade de São Caetano do Sul direcionado à educação infantil, percebe-se o propósito de se almejar uma educação que atenda as crianças de acordo com as singularidades das suas vivências, pois os elementos das culturas infantis presentes no Quadro 1 perpassam os pressupostos de encaminhamento da ação pedagógica com as crianças.

\section{CULTURAS DA INFÂNCIA NOS ANOS INICIAIS DO ENSINO FUNDAMENTAL}

A passagem da educação infantil para o ensino fundamental pode significar uma trajetória brusca caso os diferentes segmentos não estejam alinhados em algumas premissas; uma delas está intimamente relacionada às culturas da infância.

Em geral, podemos identificar muito mais claramente como essas premissas estão expressas e asseguradas quando se fala em educação infantil, pois as concepções de educação que garantem a ludicidade, a experiência e a não compartimentação do tempo e dos saberes apontam para esse caminho.

Ao passarmos para o ensino fundamental, tais premissas tendem a se dispersar um pouco mais, uma vez que os diversos campos do saber são separados em componentes curriculares atrelados também a uma arquitetura dos tempos e espaços mais fragmentados. De uma forma mais generalizante, quando se fala de ensino público no pais, ainda temos um ensino fundamental dos anos iniciais que se parece muito mais com o ensino fundamental dos anos finais do que com o ensino infantil. Isso traz implícita ou explicitamente uma concepção dos saberes da infância muito mais compartimentalizado e dualista e, consequentemente, entende os corpos em sua necessária disciplinarização para tornar o projeto viável.

Ao analisarmos o currículo em questão, podemos observar um movimento de reconhecimento de elementos da cultura da infância e como eles devem se desdobrar no cotidiano escolar, o que não significa diretamente que esses elementos já mudaram significativamente as práticas e as arquiteturas do espaço escolar, o que demandaria um novo estudo a respeito. Tais elementos, no entanto, serão apontados mais especificamente a seguir.

$\mathrm{Na}$ introdução do documento, discorre-se sobre a educação básica como um todo e, mais especificamente, sobre cada segmento que a compõe. Reconhecem-se a diversidade e as especificidades de cada etapa. Quando se destacam os elementos referentes aos anos iniciais do ensino fundamental, encontramos o seguinte:

Para os anos iniciais do Ensino Fundamental, em sua estrutura curricular é fundamental legitimar aprendizagens calcadas em situações lúdicas, realizadas com intencionalidade para entrelaçar-se às vivências da Educação Infantil. A criança, nessa fase, tem necessidades imediatas e organizar a aprendizagem em torno de seus interesses amplia o desenvol- 
vimento de seu potencial. A construção de saberes deve estar relacionada ao movimento, ao brincar, à interação com os pares (SECRETARIA MUNICIPAL DE EDUCAÇÃO DE SÃO CAETANO DO SUL, 2020, p. 41, grifos do autor).

Trata-se de uma concepção que aponta para o lúdico como elemento estruturante das ações educativas, colaborando para uma prática educativa que não dicotomiza corpo e mente, e que entende os anos iniciais como espaço para acolhimento desse corpo em constante criação, interação e movimento.

Mais ainda, no documento analisado existe uma preocupação com as transições entre os diversos segmentos de forma a assegurar uma coerência entre os diversos ciclos:

0 Ensino Fundamental é a etapa mais longa da Educação Básica, ele atende crianças e adolescentes de 6 a 14 anos, conforme prevê o Parecer CNE/CEB n. 11/2010. Dentre suas obrigatoriedades (mediante os textos da BNCC), está a de articular e a de dialogar com a Educação Infantil e com o Ensino Médio, para tecer a ponte entre os segmentos, de modo que não haja rupturas no processo de aprendizagem (SECRETARIA MUNICIPAL DE EDUCAÇÃO DE SÃO CAETANO DO SUL, 2020, p. 40).

Quando, ao discorrer sobre o ensino fundamental, fala-se sobre a necessidade de a estrutura curricular precisar "atender a demanda que chega ao Ensino Fundamental (Anos Iniciais), a fim de garantir letramentos múltiplos (ou seja, dominar os múltiplos códigos das linguagens)" (SECRETARIA MUNICIPAL DE EDUCAÇÃO DE SÃO CAETANO DO SUL, 2020, p. 41), encontramos também aí um equilíbrio entre a alfabetização e a relação entre outros códigos e linguagens vinculados às artes e à motricidade, por exemplo. Essa concepção está mais próxima tanto de garantir uma transição mais coerente entre a educação infantil e o ensino fundamental, quanto de dar espaço para que outros saberes sejam mobilizados e encarados como de igual importância ao ato educativo nos anos iniciais. Os letramentos múltiplos são, inclusive, uma chave para uma educação mais equitativa no sentido de mobilizar diversos saberes e potencialidades humanas.

É assumido no currículo um compromisso com a alfabetização nos dois primeiros anos do ensino fundamental, no entanto, para complementar essa busca, podemos nos deparar com um adendo que ressalta a importância da ludicidade e da experimentação como elementos preponderantes nessa trajetória educativa:

Importante salientar que os aspectos lúdicos e a experimentação, nos anos iniciais, são igualmente importantes para o processo de letramento e alfabetização, principalmente quando consideramos o Ensino Fundamental como um segmento que considera o continuum das aprendizagens (SECRETARIA MUNICIPAL DE EDUCAÇÃO DE SÃO CAETANO DO SUL, 2020, p. 42-43). 
Outro aspecto importante para as culturas da infância é a possibilidade de vivenciar a temporalidade de maneira mais fluida. Nesse sentido, foi criada, não só para os anos iniciais, mas para todo o ensino fundamental, uma forma de compreensão para lidar com os processos e tempos no ato educativo que é a "Roda dos Tempos". Tal dispositivo propõe, por meio de uma notação simbólica atribuída em cada objeto de conhecimento do currículo, um apontamento de tempo para flexibilizar certa homogeneização que o currículo possa significar nos processos educativos relacionados ao tempo de extensão de cada trajetória do saber. Dessa forma, por exemplo, temos objetos de conhecimento que são entendidos como longitudinais, ou seja, atravessam trimestres e perpassam o tempo usual de início e término. Para que isso se concretizasse com força, foi também estabelecido que o currículo seja entendido como anual, e, dessa forma, a gestão do tempo de realização dos processos educativos fica a cargo do educador, em relação com seus educandos, pois assim é possivel inclusive a mobilização de outros aspectos importantes e complementares dessa ação que é a leitura dos saberes prévios da turma, a relação com a territorialidade, o respeito à singularidade e a possibilidade de eleição de temáticas mais relevantes de cada turma ou coletividade.

Saindo das proposições mais gerais do currículo, podemos investigar como cada componente curricular organizou seu campo do saber e como suas premissas colaboram ou não para potencializar o respeito à cultura da infância no espaço escolar. Trataremos agora, de forma bastante panorâmica, sobre algumas premissas e temáticas abordadas por cada componente curricular diante dos anos iniciais do ensino fundamental e como cada uma se entrelaça a fim de costurar uma teia de saberes e procedimentos que possam potencializar o ato educativo e, mais especificamente, possam colaborar com uma educação mais viva e potente nos anos iniciais.

\section{AS CULTURAS DA INFÂNCIA NOS COMPONENTES CURRICULARES DO ENSINO FUNDAMENTAL I}

Podemos analisar que alguns componentes curriculares abordam mais diretamente os elementos voltados à cultura da infância e outros o fazem de forma mais indireta.

Quando nos atemos a cada campo do saber específico, percebemos que boa parte seguiu um caminho crítico e preocupado com um projeto de humanidade mais consciente, coimplicado socialmente e no território habitado, que tenha múltiplas leituras e interpretações da realidade, que acolha a diversidade - todos pontos importantes para uma sociedade justa e equitativa e que indiretamente colabora para alguns aspectos da cultura da infância.

Os componentes curriculares como Arte, Educação Física e Língua Portuguesa tiveram o conceito do rizoma (DELEUZE; GUATTARI, 1995; SOUZA, 2012) como disparador para a pro- 
dução de seus currículos; tal escolha aponta para uma elaboração ao redor do conhecimento que o entende interconectado.

0 pensamento rizomático propõe o movimento, a horizontalidade e ramificação do conhecimento, em processo contínuo e aberto. [...] No rizoma são destacados aspectos como: conexão, heterogeneidade, multiplicidade, ruptura de hierarquização e cartografia (SECRETARIA MUNICIPAL DE EDUCAÇÃO DE SÃO CAETANO DO SUL, 2020, p. 540).

Não é apenas uma opção metodológica, mas, antes disso, é a própria maneira de estruturar o pensamento, as percepções diante dos saberes e, por consequência, do ato educativo em si. As concepções apontadas anteriormente trazem o movimento, a não compartimentação dos saberes, o corpo e a experiência como gesto, motes fundamentais na caminhada educativa. São premissas que não só colaboram para as culturas da infância, como também são a própria substância que dá mais coerência para fortalecer o ato educativo em si.

Há outros entrelaçamentos conceituais entre os diferentes campos do saber descritos no currículo em análise que também apontam para o fortalecimento de uma concepção educativa focada na dialogicidade, na visão plural de territorialidade, na importância da diversidade e na construção de sentidos do ato educativo. Tais pressupostos são basilares e dão corpo e coerência para que outros pressupostos ganhem sustentação, como é o caso das culturas da infância.

Para elucidar tal apontamento, podemos trazer alguns exemplos mais precisos desses enlaces conceituais, como a questão do multiletramento, encontrada no campo da Língua Portuguesa, por exemplo, quando se incentiva tratar o conhecimento da linguagem por meio de gêneros diversos; mas também na Arte, quando se aponta para a gama de possibilidades de leitura e interpretação ligadas às múltiplas linguagens artísticas, o que propõe também a leitura em um campo não verbal ou textual, mas suas possibilidades imagéticas e corporais.

Ligada intimamente às questões do multiletramento está a interpretação, elemento complexo e de grande importância no ato educativo, pois se relaciona mais diretamente com a produção dos sentidos, com a leitura e interpretação das realidades. A interpretação e suas semioses ligam fortemente a produção do conhecimento à consciência sócio-histórica, ao vínculo com a realidade, e dão substância ao processo de construção de conhecimento.

Podemos encontrar muito fortemente proposições voltadas à interpretação nos campos da Língua Portuguesa em diversos trechos do documento, mas principalmente quando considera os estudos da sociolinguística, e na Língua Inglesa, quando propõe a percepção da interculturalidade e transculturalidade. No campo das Artes, encontramos a "experiência estética, a narratividade e a interpretação" como solo de suas proposições. No campo da Educação Física, toda a experimentação de si e na relação com o outro, no campo da motricidade humana, faz-se diante da indagação do sentido e do gesto. Mais ainda, a interpretação está presente 
muito fortemente nos campos de História e Geografia, quando propõem uma relação dialógica com o conhecimento, impulsionando o ato educativo para a análise e reflexão das distintas realidades, tempos históricos e espacialidades, a fim de proporcionar ao educando uma relação de movimento e sentido na percepção de si e do outro no tempo e no espaço.

Dessa forma, podemos vincular também a esse enlace o conceito de multiterritorialidade, encontrado muito fortemente nos campos de Língua Portuguesa, Língua Inglesa, Arte, Educação Física, História e Geografia numa percepção da diversidade territorial, étnica e cultural que propõe movimento e complexidade no ato de conhecer, aponta para a necessidade de superar as barreiras que os preconceitos e a homogeneização geram quando os elementos do conhecimento são percebidos de forma estanque.

Para esse grupo de conceitos, é importante também destacar o raciocínio lógico, indissociável da Matemática, porém importante aliado da interpretação que permite comparar, refletir, analisar, contrapor argumentos, distinguir e, por que não, criar.

Multiletramento, interpretação, multiterritorialidade e raciocínio lógico se aliam a outro conceito-chave que costura o currículo do município, que é a experiência. Tal conceito citado em todos os componentes curriculares (Matemática, Ciências, História, Geografia, Arte, Educação Física, Língua Portuguesa, Língua Inglesa e Tecnologia Educacional) mostra o reconhecimento da experiência, cada qual a seu modo, como uma aliada do conhecimento, uma vez que o tira da abstração e the atribui doses de realidade ao criar relações com o corpo, 0 tempo, o espaço e o outro. Da experiência podemos desdobrar a ludicidade, inerente à cultura da infância, que, como já mencionado anteriormente acerca da introdução do currículo, deve estar presente em todo ato educativo relacionado ao ciclo 1 do ensino fundamental. No entanto, podemos observar que a ludicidade é ainda citada no currículo em alguns componentes como uma aliada para facilitar a compreensão de aspectos específicos de seu campo do saber, ou então, no caso de Arte e Educação Física, a ludicidade é entendida com sua própria epistemologia, atrelada também à brincadeira, imaginação e criação. Essa distinção exige, por óbvio, um estudo à parte e não necessariamente é entendido assim em outros contextos.

Por fim, para finalizar este estudo sobre os anos iniciais do ensino fundamental, vale ressaltar que a leitura transversal desse trecho do documento facilitou a percepção das aproximações entre premissas comuns nos diversos campos do saber, pois estes não apontaram tão claramente tais relações; estão contextualizados em seus textos específicos, no entanto se configuram como currículo oculto quando são tomados em leituras mais abrangentes e interconectadas. Os elementos destacados nessas leituras específicas, aliados aos elementos explicitados na introdução do documento, colaboram para uma educação que percebe as especificidades e potencialidades das culturas da infância.

Cabe ainda analisar e fomentar formas de tornar essa conceituação realidade nos espaços escolares, por meio de mudanças de paradigmas por parte de educadores e do corpo gestor, 
mas também de políticas públicas que proponham mudanças mais estruturais em busca de uma maior coerência com o documento proposto.

\section{CONSIDERAÇÕES FINAIS}

Este ensaio apresentou uma proposição de quadro referencial (Quadro 1) para configurar os elementos essenciais das culturas da infância com o propósito de estabelecer um referencial de análise para o documento curricular.

Tendo o quadro como referência na análise do currículo, mais diretamente relacionado ao segmento da educação infantil, não se observaram indicações explícitas sobre as culturas da infância, mas os elementos e aspectos presentes no documento apontam a preocupação em assegurar os direitos das crianças nesse contexto.

Mesmo não sendo declarado no texto do currículo, os elementos que caracterizam as culturas infantis destacados no Quadro 1 são mais evidentes na parte que compreende o infantil, diluindo-se quando analisamos o ensino fundamental nos anos iniciais, porque o foco do documento passa a ser então os componentes curriculares e seus objetos de conhecimento e objetivos de aprendizado específicos.

\section{The right to childhood cultures: indicators in the municipal curriculum of São Caetano do Sul}

Abstract: The text is presented as an essay and aims to observe and analyze indicators in the document of the Municipal Curriculum of São Caetano do Sul that directly or indirectly address the right to childhood cultures. Methodologically, a reference framework was elaborated with some structuring elements of childhood cultures to relate it to three parts of the curriculum: the guiding principles, early childhood education and primary education I. It was observed that the curriculum under analysis pointed to several indicators in favor of the right to childhood cultures, more present in the text of early childhood education and more indirectly in the texts of elementary I, because it is more concerned with the curricular components.

Keywords: Childhood cultures. Child. Early childhood education. Elementary school. Curriculum.

\section{REFERÊNCIAS}

DELEUZE, G.; GUATTARI, F. Mil platôs: capitalismo e esquizofrenia. Rio de Janeiro: Editora 34, 1995.

JOSGRILBERG, R. de S. Para uma fenomenologia das idades da vida. Revista da Abordagem Gestáltica, v. 23, n. 3, p. 299-307, dez. 2017. 
ORGANIZAÇÃO DAS NAÇÕES UNIDAS. Transformando nosso mundo: a Agenda 2030 para o Desenvolvimento Sustentável. Rio de Janeiro: Centro de Informação das Nações Unidas para o Brasil. Disponivel em: https://nacoesunidas.org/pos2015/agenda2030. Acesso em: 17 jul. 2020.

SECRETARIA MUNICIPAL DE EDUCAÇÃO DE SÃO CAETANO DO SUL. Currículo Municipal de Educação. São Caetano do Sul, 2020. Disponivel em: https://sites.google.com/scseduca.com. br/curriculoscs. Acesso em: 21 jul. 2020.

SOUZA, R. M. de. Rizoma Deleuze-Guattariano: representação, conceito e algumas aproximações com a educação. Revista Sul-Americana de Filosofia e Educação - Resafe, n.18, p. 234-259, maio/out. 2012. Disponivel em: https://www.researchgate.net/publication/268257959_RIZOMA_DELEUZE-GUATTARIANO_REPRESENTACAO_CONCEITO_E_ALGUMAS_APROXIMACOES_ COM_A_EDUCACAO. Acesso em: 2 fev. 2021. 